\title{
"Respect when you can, resect when you should": A realistic approach to posterior leaflet mitral valve repair
}

Gilles D. Dreyfus, MD, PhD, ${ }^{\mathrm{a}}$ Filip Dulguerov, MD, ${ }^{\mathrm{a}}$ Cecilia Marcacci, MD, ${ }^{\mathrm{a}}$ Shelley Rahman Haley, MD, ${ }^{\mathrm{b}}$ Antonia Gkouma, $\mathrm{MD},{ }^{\mathrm{b}}$ Carine Dommerc, $\mathrm{PhD},{ }^{\mathrm{c}}$ and Adelin Albert, $\mathrm{PhD}^{\mathrm{d}}$

\section{ABSTRACT}

Objective: Avoiding resection to treat posterior leaflet prolapse has become popular to repair degenerative mitral regurgitation. We never subscribed to such simplification but advocated an alternative approach based on the "respect when you can, resect when you should" concept. The present study reviewed posterior leaflet prolapse in degenerative disease with the aim to expose the 10-year experience with this surgical policy, in particular long-term outcomes such as survival, recurrent/severe mitral regurgitation, and reoperation.

Methods: From January 2005 to December 2015, 701 consecutive patients with severe mitral regurgitation underwent mitral valve repair in 2 distinct institutions. Mitral regurgitation was degenerative in 441 patients, of whom the 376 with posterior leaflet prolapse constituted the study population. Patients were followed up by echocardiograms until December 2017. Longitudinal data stratified by institution were analyzed by mixed-effects models. Outcome measures were analyzed by Kaplan-Meier test.

Results: Patients with posterior leaflet prolapse $(24.7 \%$ isolated P2 and $75.3 \% \mathrm{P} 2$ associated with other segments) were aged $65.8 \pm 13$ years, and $70.5 \%$ were male. Median follow-up was 61.1 months. There were 3 hospital deaths $(0.8 \%)$. Reoperation was necessary in 7 patients (1.9\%). After 1,5 , and 10 years, overall survival was $97.8 \%, 93.6 \%$, and $86.7 \%$, respectively; the overall survival of the proportion of patients with recurrent/residual $>2+$ mitral regurgitation was estimated at $0.7 \%, 1.9 \%$, and $5.9 \%$ and that of patients with New York Heart Association III/IV at $0.8 \%, 1.9 \%$, and $5.3 \%$.

Conclusions: The "resect with respect" approach yields low operative mortality, no systolic anterior motion, good surface of coaptation, and low incidence of residual/recurrent mitral regurgitation and of reoperation, thus supporting resection when required concept. (J Thorac Cardiovasc Surg 2018;156:1856-66)

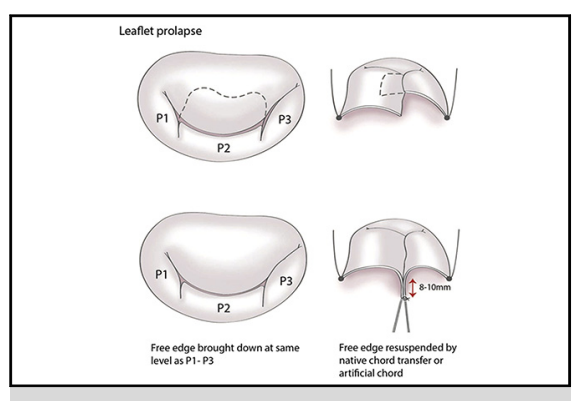

Excess height and prolapse treatment.

\section{Central Message}

In our view, despite the fact that the concept of "no resection" has become popular, limited resection is mandatory in the majority of cases to treat PLP in degenerative MR.

\section{Perspective}

Our data support the "resect with respect" concept. Our results show a low operative mortality, no SAM, a good surface of coaptation, a very low incidence of residual/recurrent $\mathrm{MR}$, and a low incidence of reoperation. Moreover, we should not teach MVr without providing younger surgeons the necessary tools to address all lesions.

See Editorial Commentary page 1867.

See Editorial page 1854 .
Mitral valve repair (MVr) is recognized as being the best treatment for severe mitral regurgitation (MR), especially when degenerative. ${ }^{1}$ Among most of the mitral maneuvers

From the a Department of Cardiac Surgery, Cardiothoracic Center of Monaco, Monte Carlo, Monaco; ' Department of Cardiology, Royal Brompton \& Harefield NHS Foundation Trust, London, United Kingdom; ' Department of Clinical Research, Cardiothoracic Center of Monaco, Monte Carlo, Monaco; and ${ }^{\mathrm{d}}$ Department of Biostatistics, University Hospital of Liege, Liege, Belgium.

Read at the 97th Annual Meeting of The American Association for Thoracic Surgery, Boston, Massachusetts, April 29-May 3, 2017.

Received for publication May 25, 2017; revisions received April 20, 2018; accepted for publication May 16, 2018; available ahead of print July 6, 2018.

Address for reprints: Gilles D. Dreyfus, MD, PhD, Cardiothoracic Center of Monaco, 11bis, Ave d'Ostende, Monte-Carlo 98000, Monaco (E-mail: gillesdreyfus1@ gmail.com).

$0022-5223 / \$ 36.00$

Copyright (c) 2018 by The American Association for Thoracic Surgery

https://doi.org/10.1016/j.jtcvs.2018.05.017 described initially by Carpentier, ${ }^{2}$ some have remained ${ }^{2}$ and others were abandoned. ${ }^{3}$ In the meantime, many have tried to simplify these techniques mainly to fit with a shorter learning curve and minimal access. ${ }^{3}$ The concept of nonresection $^{4}$ seems attractive but can be misleading for those who believe that all MVr for posterior leaflet prolapse (PLP) can be addressed that way. We disagree with such

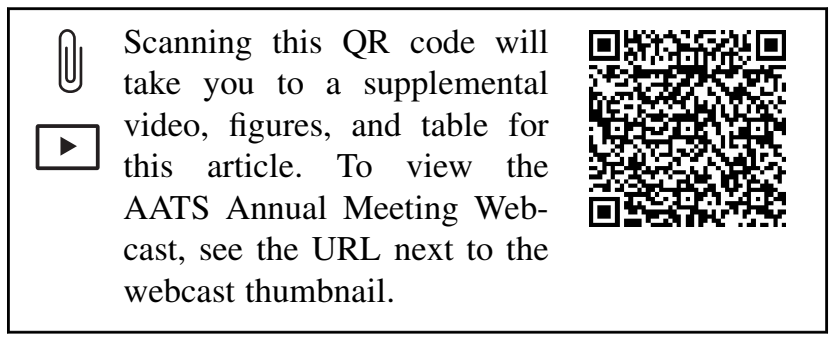




$$
\begin{aligned}
& \text { Abbreviations and Acronyms } \\
& \mathrm{AF} \quad=\text { atrial fibrillation } \\
& \text { CI = confidence interval } \\
& \mathrm{EF}=\text { ejection fraction } \\
& \text { GLMM }=\text { generalized linear mixed model } \\
& \text { LAVI = left atrium volume index } \\
& \text { LVEDD = left ventricle end-diastolic diameter } \\
& \text { LVESD }=\text { left ventricle end-systolic diameter } \\
& \text { MR = mitral regurgitation } \\
& \text { MV = mitral valve } \\
& \mathrm{MVr}=\text { mitral valve repair } \\
& \text { NYHA }=\text { New York Heart Association } \\
& \text { PASP }=\text { pulmonary artery systolic pressure } \\
& \text { PL }=\text { posterior leaflet } \\
& \text { PLP = posterior leaflet prolapse } \\
& \text { SAM }=\text { systolic anterior motion }
\end{aligned}
$$

oversimplification, which does not reflect the diversity of lesions. Excess leaflet tissue in height, excess leaflet tissue in width, and prolapse have to be analyzed before deciding which is the best strategy and which lesions should be addressed or can be ignored. We are concerned by respecting tissues as much as possible and allowing the annulus to remain intact and therefore advocate an alternative approach based on the concept "respect when you can but resect when you should." This work reports more than 10 years of experience with this surgical policy, in particular long-term outcomes such as survival, occurrence of recurrent/residual MR, and reoperation rate.

\section{MATERIAL AND METHODS Study Design}

This is a retrospective longitudinal study conducted between January 2005 and December 2015 on 701 consecutive patients with severe MR of all etiologies from 2 separate institutions (cohorts) but operated for $\mathrm{MVr}$ by the same surgeon (Dr Dreyfus). The first cohort (2005-2009, UK) consisted of patients from the Royal Brompton and Harefield NHS Foundation Trust, United Kingdom, and the second cohort (2009-2015, Monaco) included patients from the Cardiothoracic Center of Monaco. MR was degenerative in 441 patients, and among these $376(85.3 \%)$ had PLP. The latter constituted our study population. There were 129 patients from the United Kingdom and 247 patients from Monaco. The study received ethical approval from both institutions.

\section{Excess leaflet height}

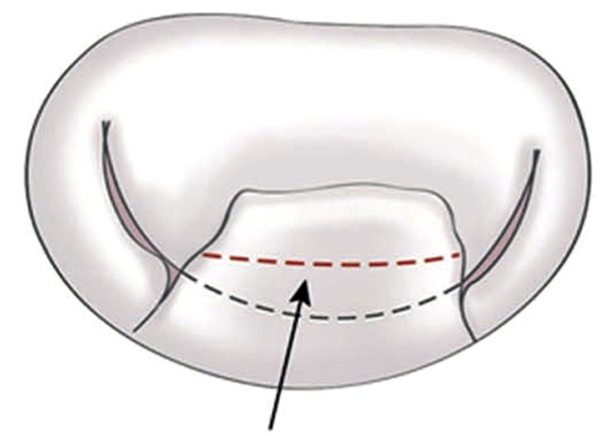

Resection line to reduce height at free edge level
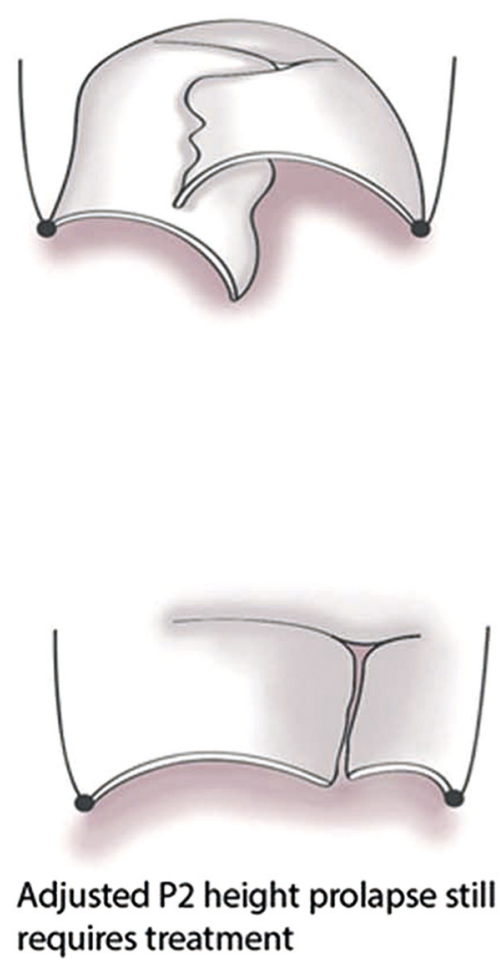

Adjusted P2 height prolapse still requires treatment

Pathological free edge,

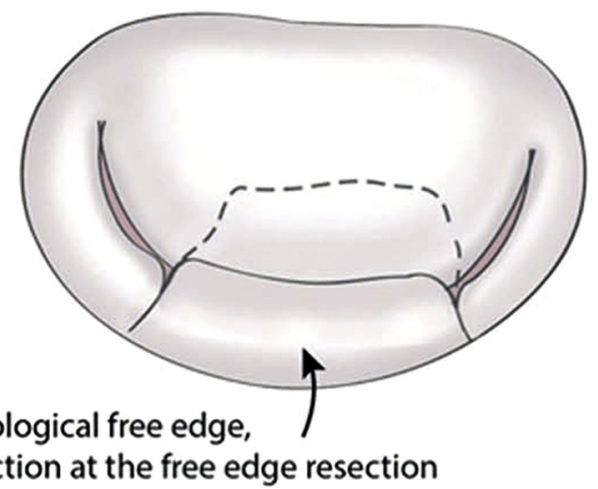

reduction at the free edge resection

FIGURE 1. Surgical strategy used in case of a pathologic process at the free edge. 


\section{Excess leaflet height}
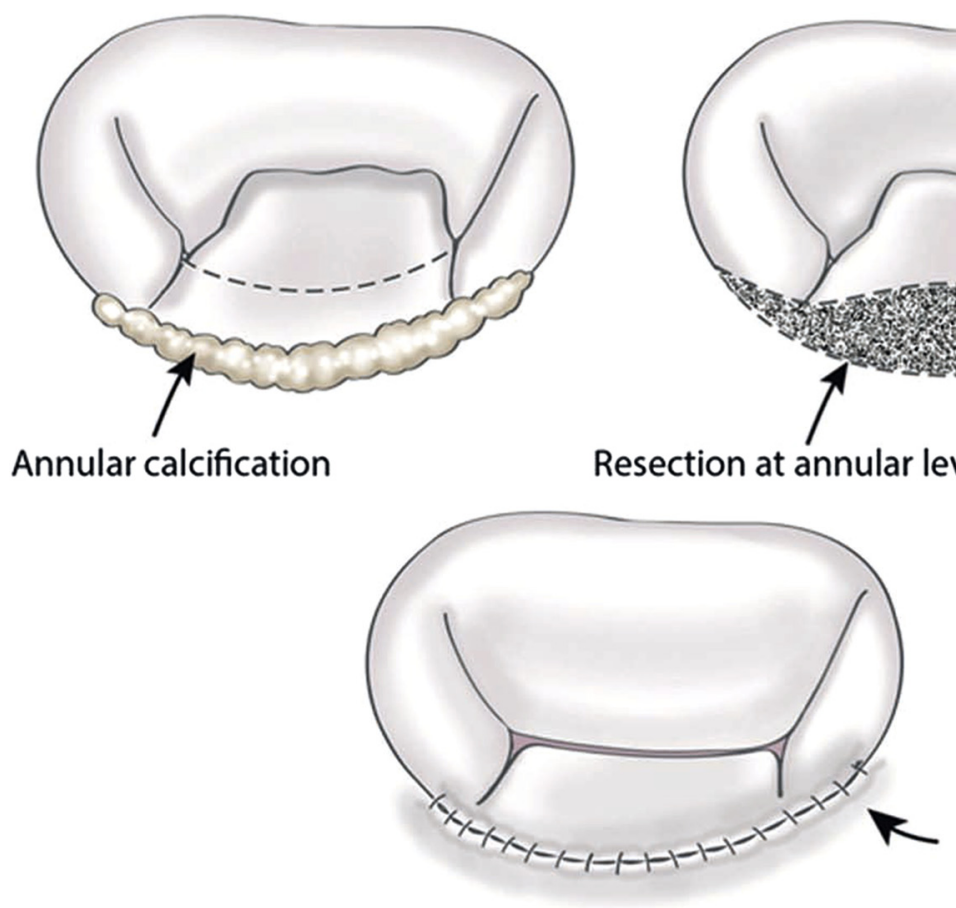

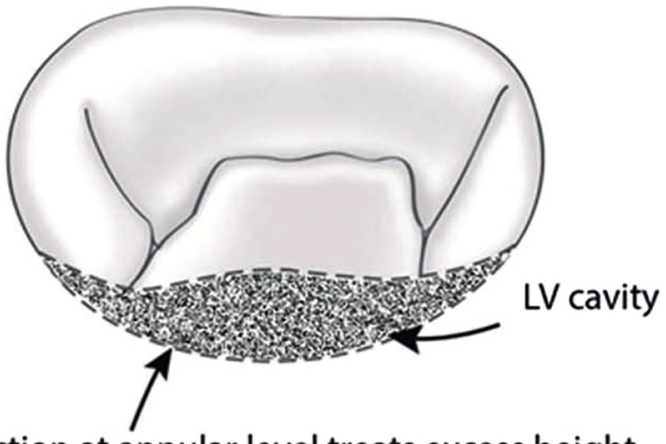

Resection at annular level treats excess height at annular level

\section{Leaflet reattached to} the annulus

FIGURE 2. Surgical strategy used in case of a pathologic process at the annular level. $L V$, Left ventricle.

\section{Operative Techniques}

Operations were performed under normothermia, and cardiopulmonary bypass was established with ascending aorta and bicaval cannulation. Myocardial protection was achieved according to the center, with cold blood intermittent cardioplegia in the United Kingdom and cold crystalloid cardioplegia (St Thomas Formula) along with topical cooling in Monaco. The mitral valve was approached through the interatrial groove. The valve was analyzed by the surgeon segment by segment, using most often P1 as a reference, both for excess tissue in height and for prolapse assessment. The presence of an excess tissue in width and the texture of the valve (eg, thickened or calcified valve, annular calcifications) were also assessed. Resection was performed only if an excess tissue in height or width was present. The excess tissue in height was treated if $\mathrm{P} 2$, after a complete unfolding, was twice as high than P1 or P3. In such cases, a transverse resection of $\mathrm{P} 2$ was performed to bring it to approximately the same height as $\mathrm{P} 1$ and $\mathrm{P} 3$ ( $\mathrm{P} 2$ being slightly higher than $\mathrm{P} 1$ and $\mathrm{P} 3$ in a normal valve). This usually removes the rough area that was thickened. During this operative step, great care was taken to individualize the secondary, and even marginal, chordae that were at the adequate length (when compared with the reference point) to resuspend the new free edge of P2. As far as the excess in width is concerned, it was treated and carried out each time there was an obvious and natural transverse folding of the leaflet. The most objective way to evaluate such an excess of tissue in width was to lay $\mathrm{P} 2$ on the posterior ventricular wall and to see if there was any natural folding. When this happened, a small triangular resection was performed, the base of the triangle being at the level of the free edge and the apex at the annulus. A small resection was often effective in eliminating the excess transverse tissue without putting the posterior leaflet (PL) under tension (Figures 1-4).

\section{Parameters Studied}

Before surgery, demographic and clinical data were recorded for each patient: age (years), gender, presence of isolated P2, New York Heart
Association (NYHA) classification (I-IV), MR grade (0-4), echocardiographic data, and presence of atrial fibrillation (AF).

During hospitalization, clinical and echocardiographic data were collected. Complications were recorded, including in-hospital death, use of intra-aortic balloon pump, inotropic support, renal failure, AF, endocarditis, implantation of pacemaker before discharge, occurrence of thromboembolism, and reoperation. The length of stay (days) was also recorded.

After hospital discharge, patients were generally seen within 3 months and then followed up annually. Clinical and echocardiographic data were collected and assessed in both institutions by experienced cardiologists with special interest in mitral valve (MV) pathology. The time occurrence of adverse events was recorded, in particular death (due to cardiac cause or not), endocarditis, thromboembolism, recurrent/residual regurgitation, $(\mathrm{MR}>2+$ ), and reoperation. Patient follow-up was stopped December 2017.

\section{Statistical Analysis}

Quantitative variables were expressed as mean and standard deviation. The median and interquartile range were used for skewed (lifetime) data. Frequency tables (numbers and percentages) were used for categoric findings. Survival and cumulative incidence curves were displayed by the Kaplan-Meier method. The competing risk framework was used to analyze time-to-event variables. Echocardiographic longitudinal data were analyzed by the generalized linear mixed model (GLMM) and tested for linear and quadratic time effects. For longitudinal ordinal data (NYHA, MR grade), the GENMOD procedure based on cumulative logits was used. Results were expressed as regression coefficients with their standard error. All statistical analyses were stratified by cohort (UK or Monaco). Confidence intervals (CIs) for proportions of patients with MR $>2+$ and with NYHA III/IV grading during follow-up were derived by the bootstrap method. Statistical calculations were carried out with SAS (SAS Institute, Inc, Cary, NC; version 9.4) package and figures with R (version 2.3.2). All tests were 2 -sided. 


\section{Excess leaflet width}

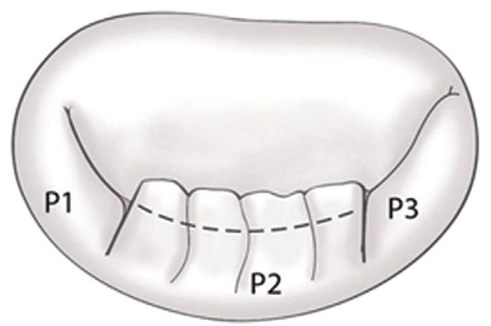

Excess width of $\mathrm{P} 2$ issue

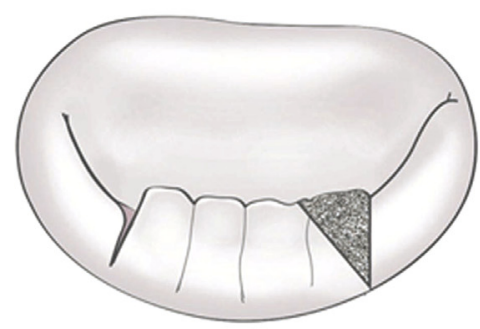

Triangular resection

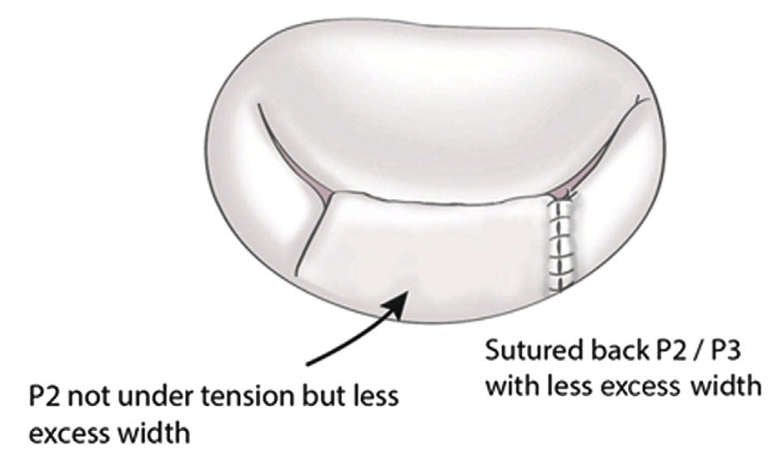

FIGURE 3. Surgical strategy used in case of excess width. $P 1$, Anterior paracommissural scallop of the posterior leaflet; $P 2$, middle scallop of the posterior leaflet; $P 3$, posterior paracommissural scallop of the posterior leaflet.

\section{RESULTS}

\section{Patient Baseline Characteristics}

Among the 376 patients with MR, 93 had isolated P2 $(24.7 \%)$ and $283(75.3 \%)$ had P2 associated with other segments of the valve ( $\mathrm{P} 1, \mathrm{P} 3$, posterior commissure, and anterior commissure). Patients' characteristics are displayed in Table 1 . The mean age was $65.8 \pm 13.0$ years, and 265 patients were male $(70.5 \%)$. According to their functional status, 137 (36.4\%) were symptomatic (NYHA III-IV). The latter were older and more often women. AF was observed in $32.4 \%$ of patients. Preoperative echocardiographic data indicated a mean ejection fraction (EF) of $65.7 \% \pm 9.2 \%$, left ventricle end-diastolic diameter
(LVEDD) of $57.8 \pm 7.4 \mathrm{~mm}$, left ventricle end-systolic diameter (LVESD) of $36.7 \pm 6.3 \mathrm{~mm}$, left atrium volume index (LAVI) of $82.5 \pm 35.3 \mathrm{~mL} / \mathrm{m}^{2}$, and a pulmonary artery systolic pressure (PASP) of $39.1 \pm 10.8 \mathrm{~mm} \mathrm{Hg}$. Almost all patients $(98.4 \%)$ had MR of grade 4 . No difference was evidenced between patients from the United Kingdom and patients from Monaco.

\section{Surgical Characteristics}

The presence of isolated P2 was confirmed intraoperatively. The mean bypass time was $130 \pm 42.6$ minutes, the mean crossclamp time $104 \pm 35.8$ minutes, and the mean size of the semi-rigid annuloplasty ring for annular dilatation was $34.2 \pm 2.9 \mathrm{~mm}$ (Table 2). The associated procedures performed during $\mathrm{MVr}$ were coronary artery bypass grafting $(12.8 \%)$, Maze procedure $(17.3 \%)$, and aortic valve replacement $(6.6 \%)$.

Following our own surgical strategy (Table 3), no resection was needed in 68 patients (18\%). Excess leaflet tissue was addressed by resecting as follows: (1) Resection for excess height was performed in 239 patients $(64 \%)$, at the free edge in 173 patients $(46 \%)$ or at the annular level in 76 patients $(20 \%)$; the choice was made according to the pathologic process localization. (2) Resection for excess width was performed in 270 patients $(72 \%)$, addressed preferably by a small triangular resection in 263 patients $(70 \%)$ and by a quadrangular resection in 7 patients $(2 \%)$. Leaflet prolapse was addressed by secondary chordal transfer in 211 patients $(56 \%)$ or by using artificial neochordae in 114 patients $(30 \%)$. A second crossclamp was required to treat residual MR in 11 patients $(3 \%)$, and successful re-repair was achieved in all patients.

\section{In-Hospital Mortality and Morbidity}

The median hospital stay was 10 days (Table 2). Three inhospital deaths occurred $(0.8 \%)$, among which 2 were of cardiac origin (low cardiac output). There were 2 kinked circumflex arteries, both treated after surgery by an angioplasty with a stenting of the circumflex. One patient had a myocardial infarction with a subsequent decrease in EF. There was no occurrence of cerebral ischemic attack, systolic anterior motion (SAM) transient or permanent, hemolysis, or infective endocarditis. One early MV failure occurred, which was successfully repaired. Among complications, there were 4 intra-aortic balloon pumps and 4 renal failures. Inotropes were administered to 78 patients $(20.7 \%)$, and permanent pacemaker implantation was necessary for 8 patients $(2.1 \%)$. Transthoracic echocardiogram at discharge showed no or trivial residual MR in 367 patients (97.6\%) and MR grade 1 in 9 patients $(2.4 \%)$.

\section{Echocardiographic Follow-up Assessment}

The median follow-up time was 61.6 months (range, 0.1-144 months). Echocardiographic longitudinal data 


\section{Leaflet prolapse}
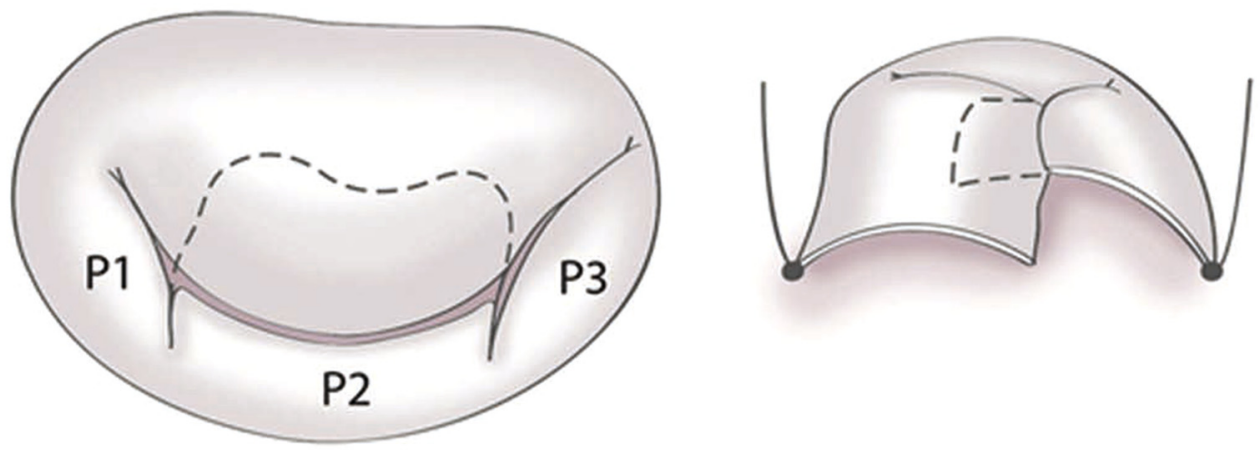

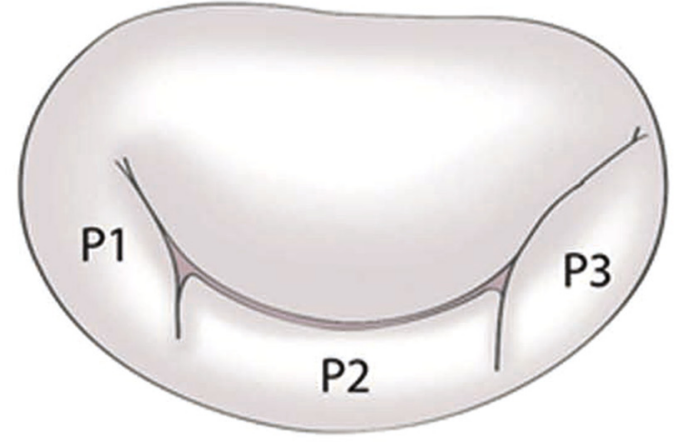

Free edge brought down at same
level as P1-P3

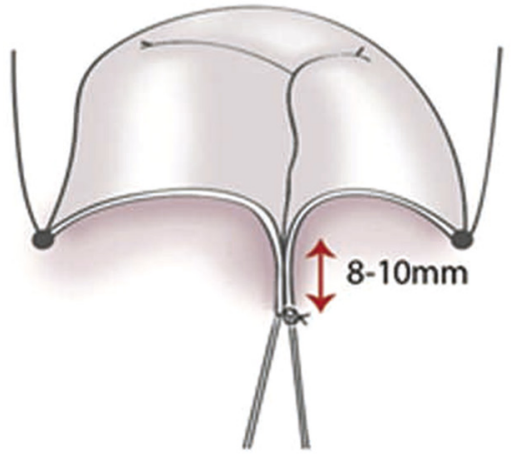

Free edge resuspended by native chord transfer or artificial chord

FIGURE 4. Prolapse treatment. $P 1$, Anterior paracommissural scallop of the posterior leaflet; $P 2$, middle scallop of the posterior leaflet; $P 3$, posterior paracommissural scallop of the posterior leaflet.

displayed in Figures E1 to E6 were analyzed by GLMM including linear and quadratic time components, preoperative parameter level, and cohort (Table E1). EF remained stable over time whereas LVEDD and LVESD exhibited a similar curvilinear evolution after MVr. Mean values remained less than $60 \mathrm{~mm}$ for LVEDD and less than $40 \mathrm{~mm}$ for LVESD. LAVI values decreased until 60 months and started to increase again thereafter, always remaining less than $60 \mathrm{~mL} / \mathrm{m}^{2}$. The PASP evolution paralleled that of LAVI, whereas left atrium-left ventricle gradient scores (not available preoperatively) did not change significantly over time. For all echocardiographic parameters except LA-LV gradient, preoperative levels were statistically significant, indicating that patients evolved in parallel of each other, ie, those with higher (lower) preoperative echocardiographic values keeping higher (lower) values throughout postoperative follow-up. Figure 5 displays the postoperative evolution of the percentage of patients with MR $>2+$. On the basis of a GLMM bootstrapped modeling, the probability of $\mathrm{MR}>2+$ was estimated at $0.7 \%(95 \% \mathrm{CI}, 0.4-1.4), 1.9 \%$ (95\% CI, 1.3-2.7), and 5.9\% (95\% CI, 3.0-11.2) at 1, 5, and 10 years after MVr, respectively. Likewise, the estimated proportion of patients with NYHA III/IV scores during follow-up is displayed in Figure 6, being respectively equal to $0.8 \%$ (95\% CI, $0.4-1.5), 1.9 \%$ (95\% CI, $1.2-2.9)$, and $5.3 \%$ $(95 \% \mathrm{CI}, 2.2-12.1)$ at 1,5 , and 10 years after $\mathrm{MVr}$, respectively.

\section{Long-Term Mortality and Complications}

Long-term mortality and complications are displayed at the bottom of Table 2. A total of 26 deaths were recorded after hospital discharge, of which 20 were of cardiac origin. Overall survival was $97.8 \%$ at 1 year, $93.6 \%$ at 5 years, and $86.7 \%$ at 10 years (Figure E7). Reoperation was necessary in 7 
TABLE 1. Patient demographic, clinical, and echocardiographic characteristics before surgery $(\mathbf{N}=376)$

\begin{tabular}{|c|c|c|c|c|}
\hline Variable & Category & Number $(\%)$ & Mean \pm SD & Range \\
\hline \multirow[t]{2}{*}{ Cohort } & UK & $129(34.3)$ & & \\
\hline & Monaco & $247(65.7)$ & & \\
\hline \multirow[t]{2}{*}{ Gender } & Male & $265(70.5)$ & & \\
\hline & Female & $111(29.5)$ & & \\
\hline Age (y) & & & $65.8 \pm 13.0$ & 21.6-89.3 \\
\hline \multirow[t]{4}{*}{ NYHA grading } & I & 179 (47.6) & & \\
\hline & II & $60(16.0)$ & & \\
\hline & III & $111(29.5)$ & & \\
\hline & IV & $26(6.9)$ & & \\
\hline \multirow[t]{5}{*}{ Echocardiogram } & $\mathrm{EF}(\%)$ & & $65.7 \pm 9.20$ & $24.0-89.0$ \\
\hline & LVEDD (mm) & & $57.8 \pm 7.40$ & $38.0-84.0$ \\
\hline & LVESD (mm) & & $36.7 \pm 6.32$ & $22.0-63.0$ \\
\hline & LAVI $\left(\mathrm{mL} / \mathrm{m}^{2}\right)$ & & $82.5 \pm 35.3$ & $19.0-230$ \\
\hline & PASP $(\mathrm{mm} \mathrm{Hg})$ & & $39.1 \pm 10.8$ & $16.0-74.0$ \\
\hline \multirow[t]{2}{*}{$\mathrm{AF}$} & No & $254(67.6)$ & & \\
\hline & Yes & $122(32.4)$ & & \\
\hline \multirow[t]{5}{*}{ MR grade } & 0 & $0(0.0)$ & & \\
\hline & 1 & $0(0.0)$ & & \\
\hline & 2 & $2(0.5)$ & & \\
\hline & 3 & $4(1.1)$ & & \\
\hline & 4 & 370 (98.4) & & \\
\hline
\end{tabular}

SD, Standard deviation; NYHA, New York Heart Association; $E F$, ejection fraction; $L V E D D$, left ventricle end-diastolic diameter; $L V E S D$, left ventricle end-systolic diameter; $L A V I$, left atrium volume index; $P A S P$, pulmonary artery systolic pressure; $A F$, atrial fibrillation; $M R$, mitral regurgitation.

patients $(1.9 \%)$, including 1 patient during hospitalization; these consisted of 3 re-repairs (after recurrent regurgitation) and $4 \mathrm{MV}$ replacements with bioprostheses. The median length of stay after reoperation was 11 days (interquartile range, 9-15 days). After 1 year, the probability of being free from reoperation was $99.2 \%$, and after 5 and 10 years this probability was equal to $98.4 \%$ and $97.1 \%$, respectively. Endocarditis was observed in only 1 patient, and thromboembolism occurred in 6 patients ( 5 transitory ischemic attacks and 1 ischemic cerebral infarction).

\section{DISCUSSION}

\section{Surgery (Video 1)}

The global philosophy of surgical techniques is based on echocardiography findings, correlated to surgical analysis. The goal is to try as much as possible to avoid tension on any part of the valve and have the nearest result to physiologic opening and closing pattern. Therefore, there is a need to treat in all patients the prolapse, the leaflets (too high, too wide, too thick, or calcified), and the annulus, which with time has lost its shape in systole. In our series, the localized prolapse (elongated or ruptured chordae) was isolated without any excess height or excess width in 68 patients $(18 \%)$. For these patients, we applied a nonresection technique as advocated by Perier and colleagues. ${ }^{4}$ However, many patients required multiple and specific maneuvers to address more complex lesions.

\section{P2 Height Issue}

Excess height is the most common lesion of $\mathrm{P} 2$ and sometimes of P1 and P3. In a normal MV, P2 is only slightly higher than $\mathrm{P} 1$ and $\mathrm{P} 3$, if not at the same height (Figure 1). The excess height going along with billowing is the result of the pathologic process. The good closure line should not be in the middle of the mitral orifice and should be regular. To achieve these goals, one has to reduce P2 height. Perier and colleagues ${ }^{4}$ advocated not to resect at all and to pull downward into the ventricle the free edge up to 6 to $8 \mathrm{~mm}$, thereby restricting $\mathrm{P} 2$ motion to treat the prolapse and excess height. We never treated excess height by restricting leaflet motion. Our philosophy has always been to treat excess height, excess width, and prolapse separately. As far as excess height is concerned, our preferred strategy is "the haircut technique," which we first described in $2006{ }^{5,6}$ The aim is to reduce the height by performing a transverse resection of $\mathrm{P} 2$. By doing so, only the excess height is addressed, and there is still the excess width to treat, if needed, and the prolapse. In rare cases $(n=43$, 
TABLE 2. Operation characteristics, in-hospital complications, and long-term outcomes $(\mathbf{N}=376)$

\begin{tabular}{|c|c|c|c|c|}
\hline Variable & Category & Number $(\%)$ & Mean \pm SD & Range \\
\hline \multicolumn{5}{|l|}{ Surgery } \\
\hline \multirow[t]{2}{*}{ Isolated P2 } & No & $283(75.3)$ & & \\
\hline & Yes & $93(24.7)$ & & \\
\hline Bypass time (min) & & & $130 \pm 42.6$ & $47.0-401$ \\
\hline Crossclamp time (min) & & & $104 \pm 35.8$ & $1.1-230$ \\
\hline Annuloplasty ring (mm) & & & $34.2 \pm 2.90$ & $28.0-40.0$ \\
\hline \multirow[t]{2}{*}{ CABG } & No & $328(87.2)$ & & \\
\hline & Yes & $48(12.8)$ & & \\
\hline \multirow[t]{2}{*}{ Maze } & No & $311(82.7)$ & & \\
\hline & Yes & $65(17.3)$ & & \\
\hline \multirow[t]{2}{*}{ AVR } & No & $351(93.4)$ & & \\
\hline & Yes & $25(6.6)$ & & \\
\hline \multicolumn{5}{|l|}{ Hospitalization } \\
\hline Length of stay (d) & Median (IQR) & & $10.0(9.0-12.0)$ & $1.0-105$ \\
\hline \multirow[t]{2}{*}{ IABP } & No & $372(98.9)$ & & \\
\hline & Yes & $4(1.1)$ & & \\
\hline \multirow[t]{2}{*}{ Renal insufficiency } & No & $372(98.9)$ & & \\
\hline & Yes & $4(1.1)$ & & \\
\hline \multirow[t]{2}{*}{ PM prior discharge } & No & $332(88.3)$ & & \\
\hline & Yes & $44(11.7)$ & & \\
\hline \multirow[t]{2}{*}{ Inotropes } & No & $298(79.3)$ & & \\
\hline & Yes & $78(20.7)$ & & \\
\hline \multicolumn{5}{|l|}{ Long-term outcomes } \\
\hline Follow-up (mo) & Median (IQR) & & $61.6(27.8-90.0)$ & $0.1-144$ \\
\hline \multirow{3}{*}{ Mortality } & In-hospital & $3(0.8)$ & & \\
\hline & Postdischarge & $26(6.9)$ & & \\
\hline & Total & $29(7.7)$ & & \\
\hline Reoperation & Yes & $7(1.9)$ & & \\
\hline Length of stay (d) & Median (IQR) & & $11.0(9.0-15.0)$ & $8.0-19.0$ \\
\hline Endocarditis & Yes & $1(0.3)$ & & \\
\hline Thromboembolism & Yes & $6(1.6)$ & & \\
\hline
\end{tabular}

$S D$, Standard deviation; $P 2$, middle scallop of the posterior leaflet; $C A B G$, coronary artery bypass grafting; $A V R$, aortic valve replacement; $I Q R$, interquartile range; $I A B P$, intraaortic balloon pump; $P M$, pacemaker.

$11.4 \%$ ), excess height and prolapse were treated with a small triangular resection, the remaining parts of the PL being at the adequate height and the adjacent chordae at the adequate length when compared with the reference point. Another option is to perform a wider triangular resection, which eliminates the excess height, excess width, and prolapsed area at the same time. We rarely if ever found lesions that could be addressed that way. Those who advocate the technique add up some folding techniques of P2. ${ }^{7}$ Carpentier ${ }^{8}$ described sliding plasty for the purpose of reducing the PL height at the level of P2 alone, or even to reduce the entire height of the PL, at the level of P1, P2, and P3. We used Carpentier sliding plasty with a quadrangular resection in only 4 patients $(1 \%)$. After having resected for excess height, the new P2 leaflet requires the free edge to be supported, thereby treating the prolapse component in 211 patients with native chordal transfer $(56.1 \%)$ and in 114 patients with artificial chordae
$(30.3 \%)$. If the free edge did not show any pathologic process or elongated or ruptured chordae, but most often in such instances a billowing of $\mathrm{P} 2$, we then addressed the issue of leaflet height by reducing it at the annular level. We detached the leaflet from the annulus, resected some leaflet tissue, and reattached the leaflet to the annulus without any transverse displacement. This is what we call a "false sliding." We also used this maneuver in case of a pathologic process at the annular level, such as a calcified annulus that required decalcification (Figure 2).

\section{Excess Width}

Excess width was emphasized in our 2006 publication, when we advocated using small triangular resections to treat excess width (Figure 3); the concept was later reinforced by Perier and colleagues. ${ }^{4}$ In their "Discussion" section, they reported that up to $35 \%$ of cases required triangular resection because of excess tissue in width. 
TABLE 3. Posterior leaflet surgical strategy $(N=376)$

\begin{tabular}{lccc}
\hline \multicolumn{1}{c}{$\begin{array}{c}\text { Resection of } \\
\text { excess tissue }\end{array}$} & At free edge & $\begin{array}{c}\text { At annular } \\
\text { level }\end{array}$ & Triangular \\
\hline Height & Yes & Yes & No \\
$\mathrm{N}=239(64 \%)$ & $\mathrm{N}=173(46 \%)$ & $\mathrm{N}=76(20 \%)$ & \\
$\mathrm{Width}$ & No & No & Yes \\
$\mathrm{N}=270(71.8 \%)$ & & $\mathrm{N}=263(70 \%)$ \\
& & Quadrangular, \\
& & $\mathrm{N}=7)$ \\
\hline \multicolumn{1}{c}{ Prolapse } & Resection & Free edge \\
treatment & No & Yupport \\
\hline Localized & (no excess tissue) & Native chordae \\
$\mathrm{N}=68(18 \%)$ & & $\mathrm{N}=18(5 \%)$ \\
& & Neochordae \\
& & $\mathrm{N}=55(14 \%)$ \\
& Yes & No \\
Segmental & (resection removed & $($ adjacent chordae \\
$\mathrm{N}=43(11.4 \%)$ & prolapsed area) & sufficient) \\
& Yes & Yes \\
Extensive & (but not to address & Native chordae \\
$\mathrm{N}=308(82 \%)$ & prolapse, only for & $\mathrm{N}=211(56.1 \%)$ \\
& excess tissue) & Neochordae \\
& & $\mathrm{N}=114(30.3 \%)$ \\
\hline
\end{tabular}

We resected the width in 270 patients $(71.8 \%)$, among whom 263 had triangular resections $(97.4 \%)$. In our view, the best criterion indicating that there is no excess tissue in width is to be able to apply the entire PL without any tension along the posterior wall of the LV. A normal MV never shows such excess tissue as seen in a diseased valve. In a recent meta-analysis, Mazine and colleagues ${ }^{9}$ claim that chordal replacement is superior to leaflet resection in PLP because the mean gradient seems lower in chordal replacement as opposed to leaflet resection. In our series, the mean is less than $3 \mathrm{~mm} \mathrm{Hg}$ and does not support this concept. Moreover, limited triangular leaflet resection

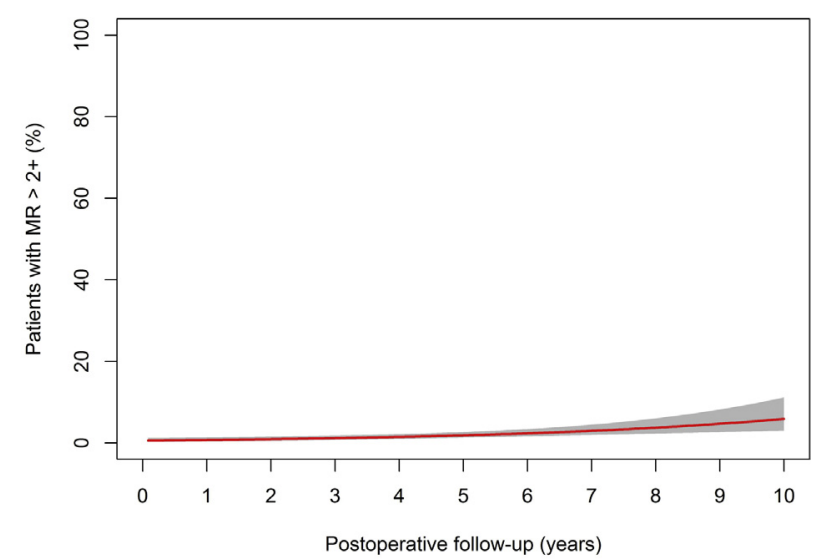

FIGURE 5. Evolution of the percentage (with $95 \%$ bootstrapped confidence bands) of patients with MR $>2+$ during postoperative follow-up $(\mathrm{N}=376) . M R$, Mitral regurgitation.

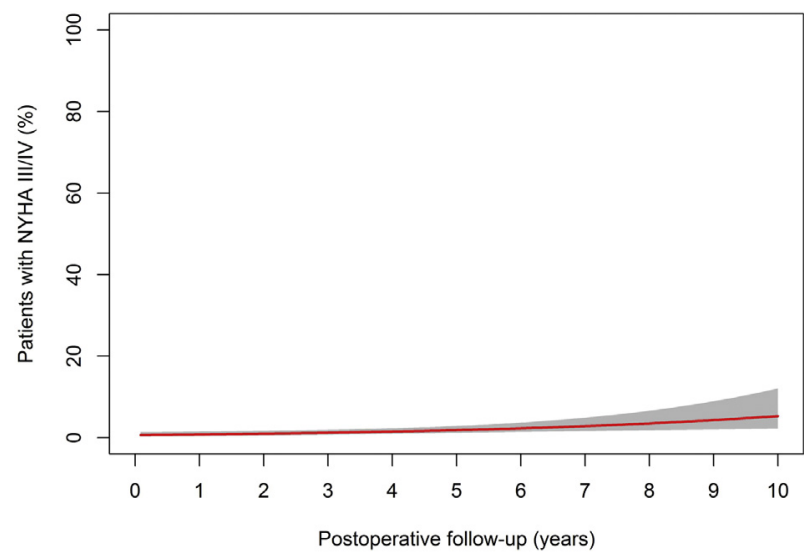

FIGURE 6. Evolution of the percentage (with 95\% bootstrapped confidence bands) of patients with NYHA grading III/IV during postoperative follow-up $(\mathrm{N}=376)$. NYHA, New York Heart Association.

does not imply annular folding and therefore has no impact on the size of the annuloplasty ring. We completely agree with Tomsic and colleagues ${ }^{10}$ and Perier and colleagues, ${ }^{4}$ who resect when there is excess width. This message was recently reinforced by Antunes. ${ }^{11}$

\section{Prolapse}

Some might be challenged by our extensive use of native chordae (211 patients, $56.1 \%$ ) as opposed to artificial chordae (114 patients, 30.3\%). Several patients required both. First, secondary chordae are often, if not always, at the adequate length when compared with the reference point. Transferring and reattaching them relieve the burden of finding the adequate length, which remains an issue when using multiple artificial chordae. This issue grows further with the number of artificial chordae being used. We detached the secondary chordae with some tissue of the ventricular aspect of the leaflet, allowing with a monofilament $5 / 0$ mattress suture to reattach it at the free edge level. Thus far, we have never seen such a chord failing at an early stage or in a later reoperation for another purpose. The number of native or artificial chordae used per patient is rather small when compared with others (mean, 2; range, 1-4). The reason is that the use of chordae is limited to treat the prolapse (Figure 4) and not to compensate the absence of resection. ${ }^{12}$ At this stage, a conventional water test is always performed without annuloplasty ring and sutures. If the water test is not perfect, we look for remaining problems, but we never rely on the annuloplasty to eradicate a residual leak. We used annuloplasty rings in all patients (Physio I and II; Edwards Lifesciences, Irvine, Calif), measuring the size according to the unfolded anterior leaflet and always using the upper size in case of doubt. In our view, an annuloplasty is always mandatory to reshape the annulus and to decrease the tension on it. ${ }^{13}$ The ultimate goal of all mitral repair strategies is to decrease excess tension at each 


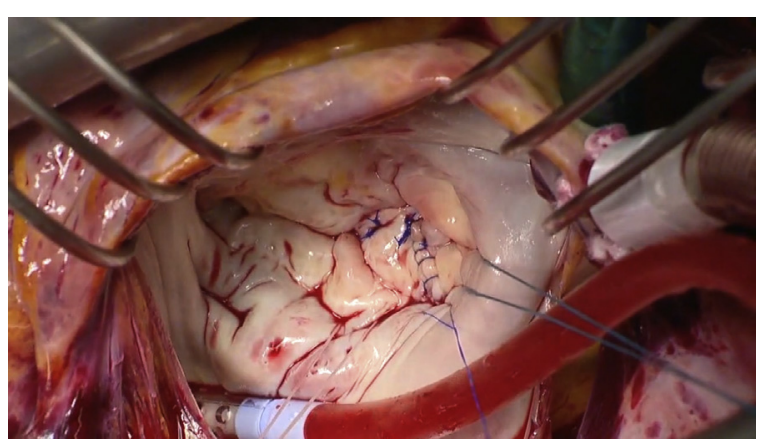

VIDEO 1. Surgical strategy. Excess height, excess width, and prolapse are analyzed and treated separately. Video available at: https://www.jtcvs.org/ article/S0022-5223(18)31437-5/fulltext.

and every level of the mitral apparatus. Therefore, we believe that oversimplification is applicable to all mitral repairs, such as artificial chordae and ring annuloplasty; however, patients need to do well early and later to maintain mitral repair as the gold standard. ${ }^{14}$ Little is known about the long-term results of those advocating such simplification.

\section{Systolic Anterior Motion}

SAM is a major and frequently reported issue. Jebara and colleagues ${ }^{15}$ gave a pathophysiologic explanation of SAM, clearly stating that PL height was the main triggering factor. ${ }^{16}$ For a considerable period of time, despite this publication, the rigid ring annuloplasty was considered to be responsible for SAM. Subsequently, bands or incomplete rings were developed, and the SAM issue still remained a concern. We never observed a single SAM intraoperatively or later on. This can be related only to our systematic approach of the PL height to bring P2 at the same level as $\mathrm{P} 1$ and $\mathrm{P} 3$, which in turn brings the coaptation area backward, close to the posterior wall of the left ventricle, away from the outflow tract.

\section{Study Limitations}

Although this study involved a large number of patients from 2 different centers, it reports the experience of a single cardiac surgeon. This does not perfectly reflect the variability of more general surgical and medical practices and habits; however, it could be considered as a strength of the study given that all patients were treated in exactly the same way. Likewise, the interpretation of ultrasound data was performed in each center by a single cardiologist with particular interest in mitral pathology; there was no real core laboratory design. This retrospective longitudinal study of patients with MR suffers from the weaknesses of retrospective studies, including selection biases, reliability, quality, and completeness of data collected from patient files. Finally, although based on 2 cohorts, the study did not include a control group of any kind.

\section{CONCLUSIONS}

The study conveys the message that to achieve good and durable MR repair, there is a need to treat excess tension at every level: chordae, leaflets, and annulus. By doing so, it is possible to respect the entire valve in approximately $20 \%$ of the cases, but the majority of cases $(80 \%)$ require associated maneuvers. The ultimate goals should remain a low postoperative mortality, a low incidence of moderate/severe $\mathrm{MR}$, and a very low incidence of reoperation. Resection should not be abandoned, because in our experience it is a key point in the treatment of most PL degenerative MV diseases. These are the reasons why we should respect whenever possible and resect whenever needed.

\section{Webcast}

You can watch a Webcast of this AATS meeting presentation by going to: https://aats.blob.core.windows. net/media/17AM/2017-05-02/BallroomABC/05-02-17_ BallroomABC_1620_Dreyfus.mp4.

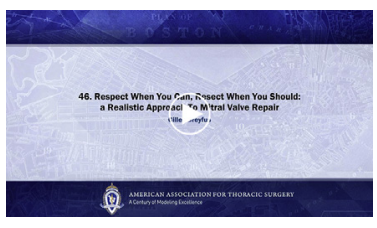

\section{Conflict of Interest Statement}

Dr Dulguerov reports personal fees from Edwards Lifesciences for an education course, outside the conduct of the study. Dr Rahman Haley reports non-financial support from Edwards Lifesciences, outside the conduct of this study. All other authors have nothing to disclose with regard to commercial support.

\section{References}

1. Gillinov AM, Blackstone EH, Nowicki ER, Slisatkorn W, Al-Dossari G, Johnston DR, et al. Valve repair versus valve replacement for degenerative mitral valve disease. J Thorac Cardiovasc Surg. 2008;135:885-93.

2. Carpentier A. Cardiac valve surgery: the "French correction" J Thorac Cardiovasc Surg. 1983;86:323-37.

3. Filsoufi F, Carpentier A. Principles of reconstructive surgery in degenerative mitral valve disease. Semin Thorac Cardiovasc Surg. 2007;19:103-10.

4. Perier P, Hohenberger W, Lakew F, Batz G, Urbanski P, Zacher M, et al. Toward a new paradigm for the reconstruction of posterior leaflet prolapse: midterm results of the "respect rather than resect" approach. Ann Thorac Surg. 2008;86:718-25.

5. Dreyfus GD, Corbi P, Rubin S, Aubert S. Posterior leaflet preservation in mitral valve prolapse: a new approach to mitral repair. J Heart Valve Dis. 2006;15:528-30.

6. Chitwood WR Jr. Haircut mitral valve repair: posterior leaflet-plasty. Ann Cardiothorac Surg. 2015;4:387-92.

7. Suri RM, Burkhart HM, Schaff HV. A novel method of leaflet reconstruction after triangular resection for posterior mitral valve prolapse. Ann Thorac Surg. 2010;89:53-6.

8. Carpentier A. The sliding leaflet technique. Le Club Mitrale Newsletter. 1988;1: 2-3.

9. Mazine A, Friedrich JO, Nedadur R, Verma S, Ouzounian M, Juni P, et al. Systematic review and meta-analysis of chordal replacement versus leaflet resection for posterior mitral leaflet prolapse. J Thorac Cardiovasc Surg. 2018;155:120-8.e10.

10. Tomsic A, Klautz RJ, Palmen M. Respect versus resect: two different repair techniques or two different tools in the box? J Thorac Cardiovasc Surg. 2018;155: $600-1$. 
11. Antunes MJ. Isolated posterior mitral leaflet prolapse: resect, respect, or resect with respect? J Thorac Cardiovasc Surg. 2018;155:129-30.

12. Padala M, Cardinau B, Gyoneva LI, Thourani VH, Yoganathan AP. Comparison of artificial neochordae and native chordal transfer in the repair of a flail posterior mitral leaflet: an experimental study. Ann Thorac Surg. 2013;95:629-33.

13. Nardi P, Pellegrino A, Olevano C, Scafuri A, Lio A, Polisca P, et al. Mitral valve repair for the treatment of degenerative mitral valve disease with or without prosthetic ring annuloplasty: long-term outcomes. J Cardiovasc Surg. 2013;54:305-12.

14. Braunberger E, Deloche A, Berrebi A, Abdallah F, Celestin JA, Meimoun P, et al. Very long term results (more than 20 years) of valve repair with Carpentier's techniques in non rheumatic mitral valve insufficiency. Circulation. 2001; 104(12 Suppl 1):I8-11.

15. Jebara VA, Mihaileanu S, Acar C, Brizard C, Grare P, Latremouille C, et al. Left ventricular outflow tract obstruction after mitral valve repair. Result of the sliding leaflet technique. Circulation. 1993;88(5 Pt 2):II30-4.

16. Carpentier A. The SAM issue. Le Club MitraleNewsletter. 1989;1:72-5.

Key Words: annuloplasty, echocardiogram, endocarditis, leaflet prolapse, leaflet tissue, mitral valve repair, regurgitation, reoperation, thromboembolism

\section{Discussion}

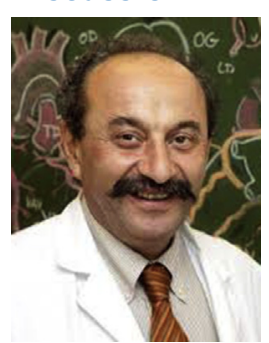

Dr Gebrine El Khoury (Brussels, Belgium). Excellent presentation and results. I like your title. When I saw it for the first time, I said, well, that's what all of us are doing: We respect and we resect when it is necessary. It sounds to me like a philosophical session; all of us are doing the same. Let's go to the patients. You said that 25\% of your patients had isolated P2 prolapse. Well, we know in the literature that $75 \%$ are localized or $\mathrm{P} 2$ prolapse. Are we as cardiac surgeons missing $75 \%$ of lesions or misinterpreting the echo or mis-assessing during surgery? What do you think about that?

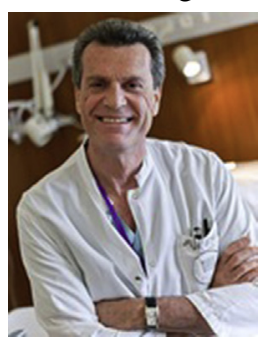

Dr Gilles D. Dreyfus (Monte Carlo, Monaco). Philosophy? I think that I was arguing a more philosophical motto, which is respect rather than resect, and I think also a dangerous one, because there are more new surgeons willing to perform minimally invasive surgery who do not have the capacity to analyze the valve surgically and therefore rely only on the echo. I don't say you can't, but I think then you need to really have a very good echocardiographer who is reliable and knows exactly what surgery is about.

Second, this is, of course, what everybody says they do but it's not what they do in the real world. As you know perfectly and you travel like me, we don't see many surgeons resecting and treating all lesions.

Now, to answer your question about the discrepancy between these $25 \%$ that we had and the $75 \%$ of the literature I cannot explain unless I am treating every type of disease, for instance, if I may take an example, if I want to achieve a posterior leaflet that is nearly at the same height for P1,
$\mathrm{P} 2$, and $\mathrm{P} 3$ as it is in a normal valve; a normal valve does not have a P2 twice higher than P1 and P3. A lot of people do not care about that. So perhaps I am overtreating; this is what you probably are alluding to when you say that. Well, I think that if I have a P3 that is twice P1 and the same side as $\mathrm{P} 2$, I reduce the height by a Gore-Tex chord or by resection at the annulus.

Dr El Khoury. Those lesions are not necessarily prolapse. You can have billowing, you can have a restricted valve.

Dr Dreyfus. Yes, I think we agree. What we all aim for is to have an evenly distributed closure line parallel to the posterior rim, three-fourths/one-fourth, and a good surface of coaptation, and that's all.

Dr El Khoury. Your echocardiographer is not very busy before the surgery. You analyze really what you rely on, your surgical analysis.

Dr Dreyfus. No, no. We have echos. We have a strategy, which is a transthoracic echo. If we have any doubt, we do a transesophageal echo preoperatively, we do a transesophageal echo intraoperatively before going on pump, and we crosscheck by surgical analysis. A surgical analysis always supersedes an echocardiogram.

Dr El Khoury. Let's go for the surgery itself now, for the excess height and excess width. It's what Dr David also referred to as excess volume. What are the criteria that we really need? What is excess height, what is excess width? Is it double P1, double P3?

Dr Dreyfus. Excess height is easy to identify, because, again, it is referring to P1 or P3. I think the $2 \mathrm{~cm}$ that was described by Carpentier is even too high. I would say the shorter you can make the posterior leaflet the better you will have the mitral repair. Now, the width, basically you should be allowing the posterior leaflet to lie along the posterior wall smoothly without any folding or curling of the valve.

Dr El Khoury. To see this folding, do you agree that maybe the best way to do that is to do a water test before the surgery and try to push the P2 inside?

Dr Dreyfus. Well, some do that. I don't do that. I think this is a training pattern. I was trained under Carpentier, and we never did a water test before. We relied on the surgical analysis. But you see that, obviously. When you have a myxomatous valve, you can see how redundant the tissue is, how thick, how in excess it is in both dimensions, width and height.

Dr El Khoury. For the secondary chordae you use to repair the prolapse when you do the free margin resection, you also use Gore-Tex?

Dr Dreyfus. Of course. It is not a religious belief. I use both native chords because I find it easy. I'm lazy. The native secondary chords are always at the adequate height.

Dr El Khoury. It is difficult to do this secondary chordae. Do you agree that we can put, easily, Gore-Tex on that?

Dr Dreyfus. Of course I do. 
Dr El Khoury. You are not really religiously opposed? Dr Dreyfus. No, no, no, no religious belief.

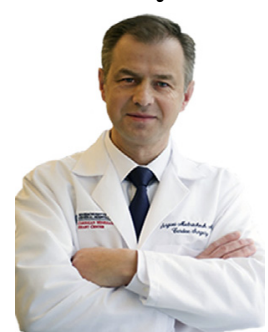

Dr Serguei Melnitchouk (Boston, Mass). My question is regarding pathology. As I remember correctly, $76 \%$ of your patients had myxoid degeneration, which leaves $24 \%$ with, I guess, fibroelastic deficiency; however, only $6 \%$ had no resection. What is your comment to those surgeons who prefer to use neochords in those patients in whom you have paucity of tissue and not so much resection? I understand myxoid degeneration, but in fibroelastic deficiency cases, some surgeons prefer to use a more neochordal technique.

Dr Dreyfus. It does reflect our practice and what we see. If there is excess tissue and we will not achieve an evenly distributed closure line and surface of coaptation, we will resect in addition to resuspend the prolapse, whatever the cause is. I agree with you the tendency would be that the fibroelastic deficiency would have less excess tissue. Now, it is not so clearly defined; evaluated fibroelastic deficiency probably has excess tissue. I don't have a precise answer to your question. I don't resect for the sake of resecting.

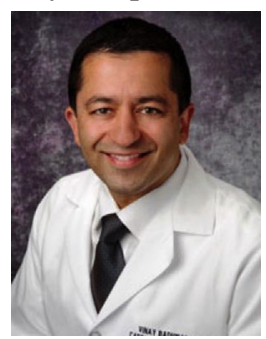

Dr Vinay Badhwar (Morgantown, $W V a)$. You are educating us on the art form of doing MVr.

Dr Dreyfus. I don't want to educate anybody.

Dr Badhwar. For the interpretation of your article, it seems these are all cases you have done personally, and we know that experience matters. So one can judge operative strategy based on the anatomic assessment and experience. What take-home message can you give the audience on the specific leaflet anatomic criteria? To summarize your presentation on your decision to resect, is it height, depth, or simply the disease state?

Dr Dreyfus. It is a difficult and good question you are asking me, to summarize such a thing. I do not want to appear as willing to take the counterpart of Patrick Perier's philosophy, which says, I never resect, and I'm not saying that I do resect every time. We have had debates together; we do tend to agree. He does resect only in $35 \%$ to $40 \%$ of the cases. I resect approximately $60 \%$ of the cases, but basically the philosophy is the same. We wouldn't like to leave tissue that is not pliable or soft, and that would affect the early and long-term outcomes.

Dr Badhwar. So it appears we have equipoise in technique and good results with both.

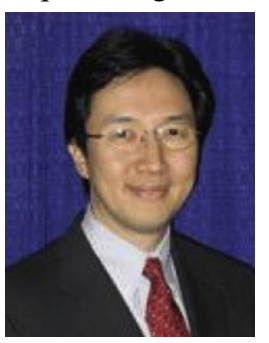

Dr Tohru Asai (Otsu, Japan). A short comment. I totally echo that. I also received traditional training. But recently I switched to a more focused approach with height reduction, what I call a butterfly technique. Do you have any problem with annular compression or plication in your larger series of patients sometimes? What do you think about our approach?

Dr Dreyfus. If this approach works, it's fine. I do not use compression sutures. I water test all the patients after the repair, having treated the prolapse, the excess tissue, basically the chordae, the leaflets, and then I do a water test with no ring and no sutures at all, and it shouldn't leak. If it leaks at that stage, there is something wrong, and the annuloplasty will not sort it out whether they are compressing or not. So I don't think the ring was meant in any way to treat a prolapse, excess tissue, or billowing.

Dr Asai. I agree. What is the final height of the P2 and P1, the target height?

Dr Dreyfus. As I said, normally, unless you have a extensive myxoid valve, P1 is usually the one that is at the adequate height, but if it is more than $1.5 \mathrm{~cm}$, I would reduce the height. 

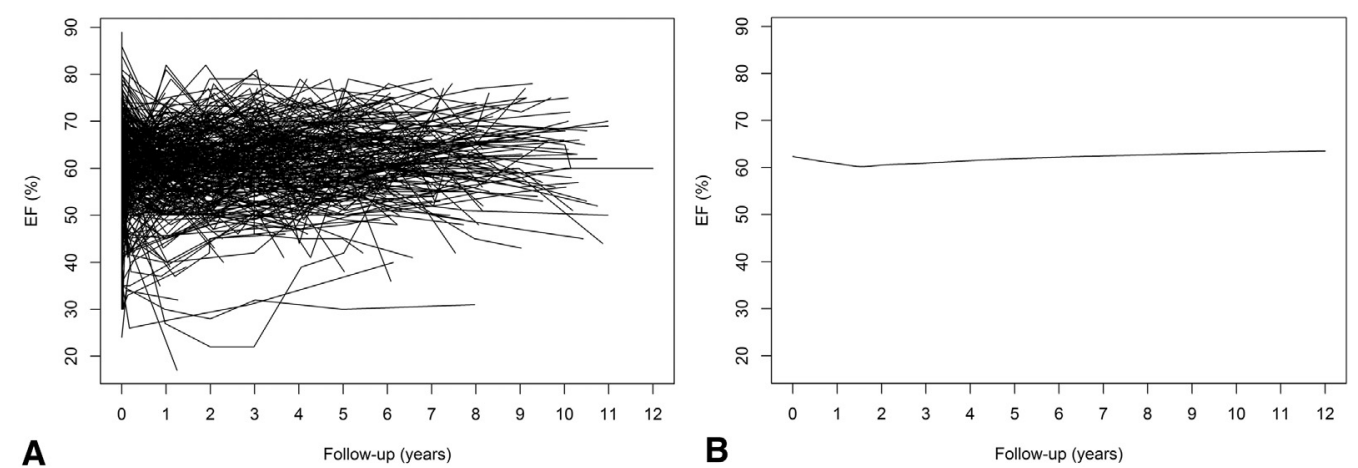

A

Follow-up (years)

\section{B}

Follow-up (years)

FIGURE E1. Individual evolutions (A) and smoothed average evolution (B) of EF (\%) during follow-up of 376 patients receiving MVr. EF, Ejection fraction.
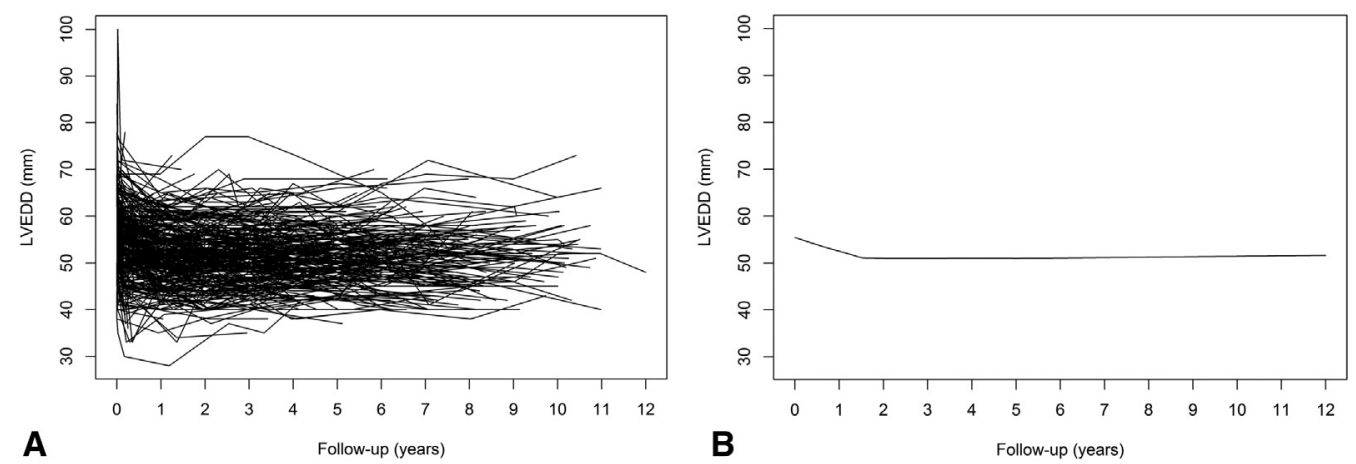

FIGURE E2. Individual evolutions (A) and smoothed average evolution (B) of LVEDD (mm) during follow-up of 376 patients receiving MVr. LVEDD, Left ventricle end-diastolic diameter.

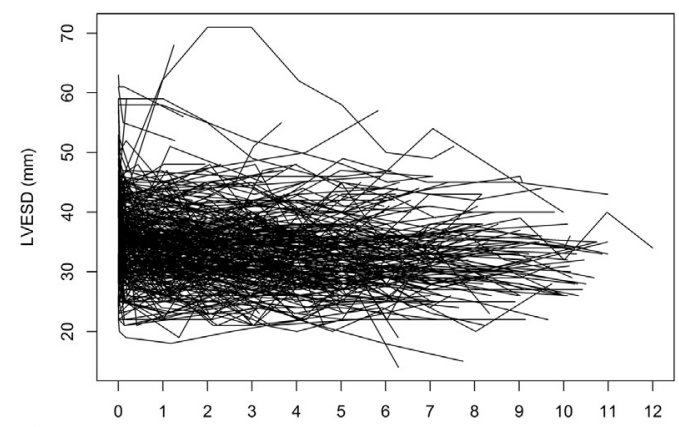

A

Follow-up (years)

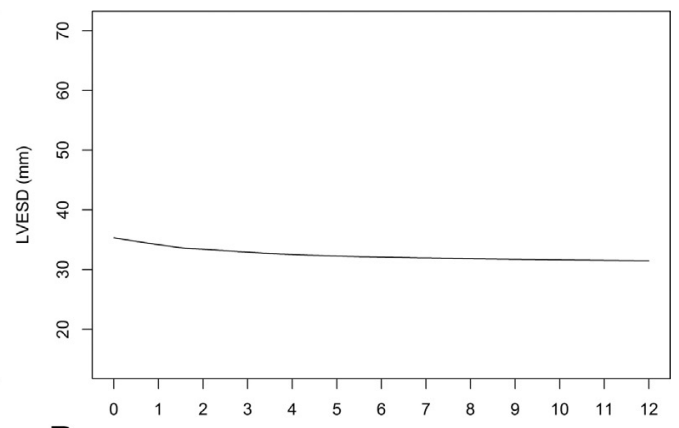

B

FIGURE E3. Individual evolutions (A) and smoothed average evolution (B) of LVESD (mm) during follow-up of 376 patients receiving MVr. LVESD, Left ventricle end-systolic diameter. 

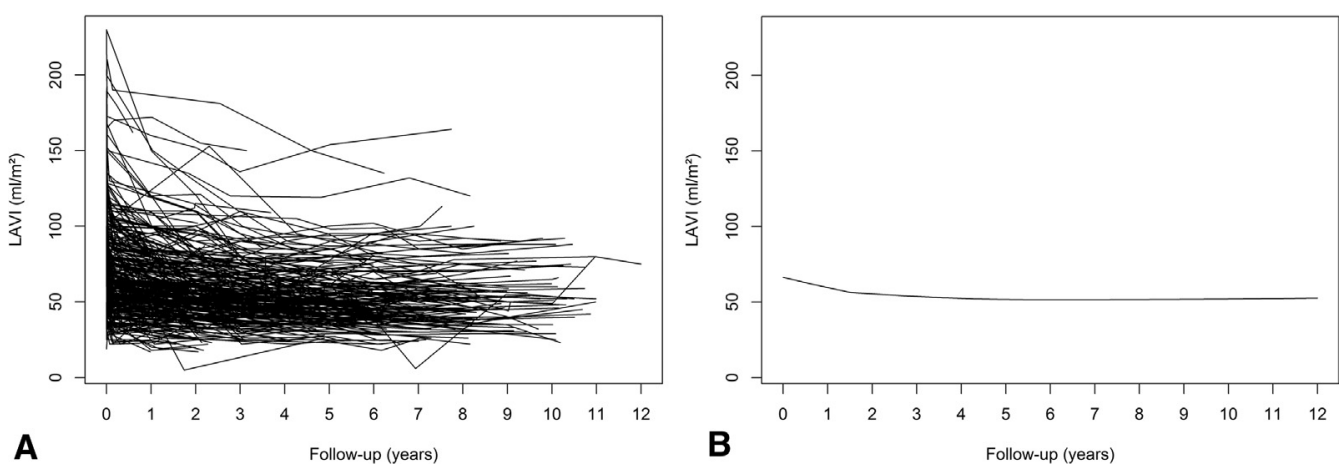

FIGURE E4. Individual evolutions (A) and smoothed average evolution (B) of LAVI ( $\mathrm{mL} / \mathrm{m}^{2}$ ) during follow-up of 376 patients receiving MVr. LAVI, Left atrium volume index.
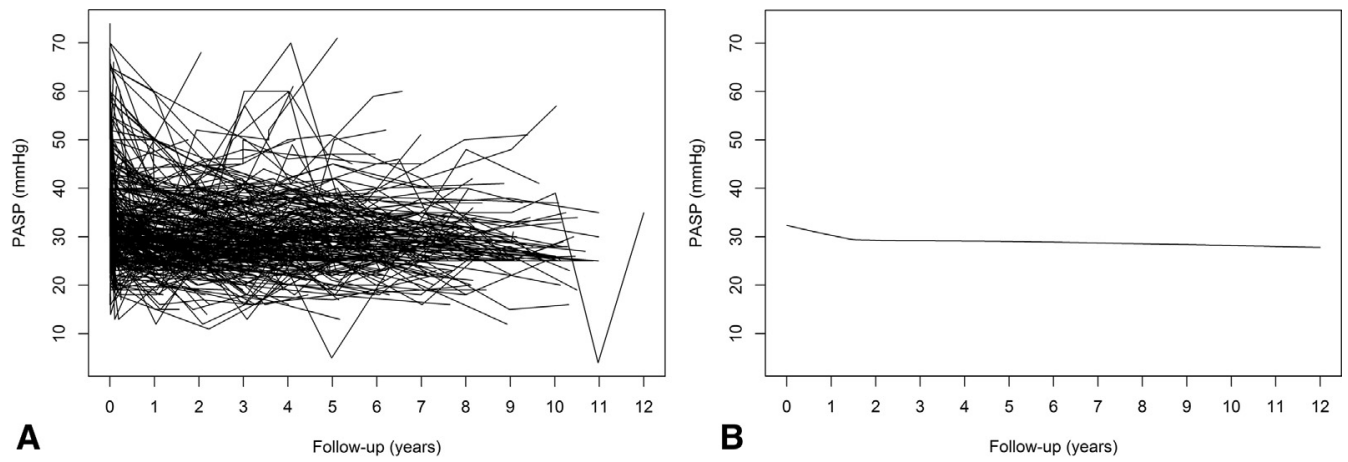

FIGURE E5. Individual evolutions (A) and smoothed average evolution (B) of PASP (mm Hg) during follow-up of 376 patients receiving MVr. PASP, Pulmonary artery systolic pressure.

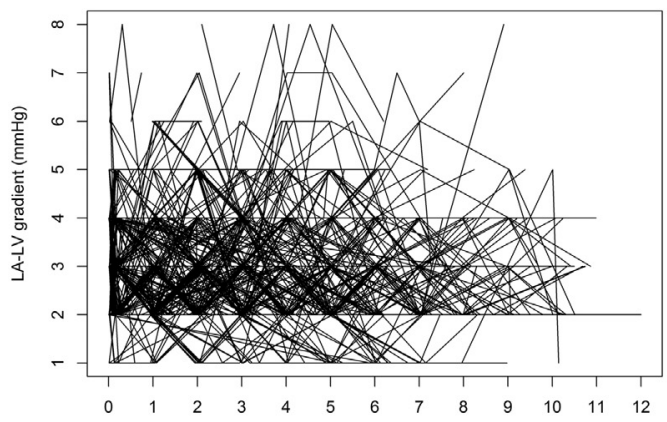

A

Follow-up (years)

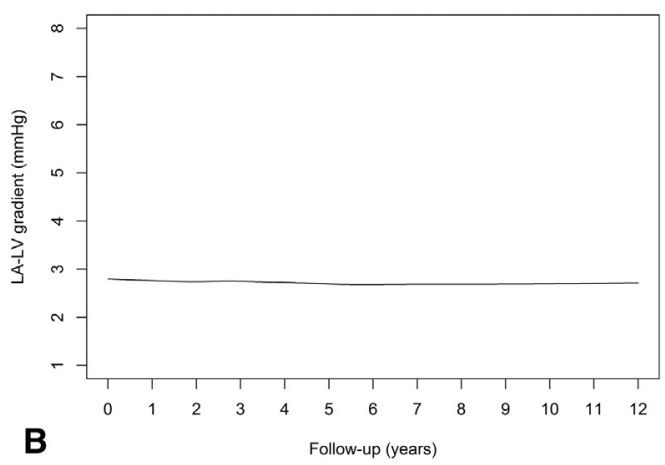

B

Follow-up (years)

FIGURE E6. Individual evolutions (A) and smoothed average evolution (B) of left atrium-left ventricle gradient (mm $\mathrm{Hg}$ ) during follow-up of 376 patients receiving MVr. $L A-L V$, Left atrium-left ventricle. 


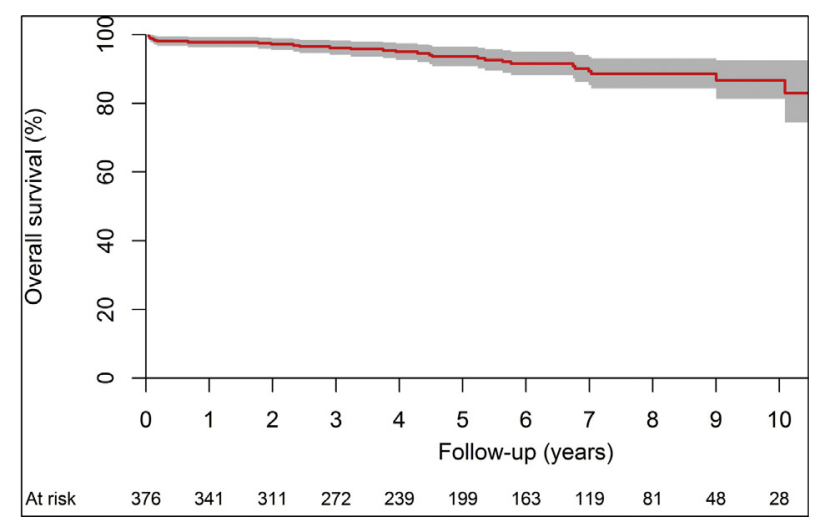

FIGURE E7. Overall survival after $\mathrm{MVr}(\mathrm{N}=376)$.

TABLE E1. Longitudinal echocardiographic data modeled by linear mixed-effects models adjusted for cohort $(\mathbf{N}=376)$

\begin{tabular}{|c|c|c|c|c|}
\hline Parameter & Linear time effect $(t)$ & Quadratic time effect $\left(t^{2}\right) \times 10^{-2}$ & Preoperative level effect & Intercept(s) \\
\hline \multirow[t]{2}{*}{$\mathrm{EF}(\%)$} & $-0.024 \pm 0.014$ & $0.031 \pm 0.014 *$ & $0.48 \pm 0.026^{*}$ & $29.1 \pm 1.80^{*}$ \\
\hline & $P=.074$ & $P=.023$ & $P<.0001$ & \\
\hline \multirow[t]{2}{*}{ LVEDD (mm) } & $-0.15 \pm 0.0091^{*}$ & $0.10 \pm 0.0092^{*}$ & $0.54 \pm 0.028^{*}$ & $24.3 \pm 1.65^{*}$ \\
\hline & $P<.0001$ & $P<.0001$ & $P<.0001$ & \\
\hline \multirow[t]{2}{*}{ LVESD (mm) } & $-0.078 \pm 0.007^{*}$ & $0.036 \pm 0.0079^{*}$ & $0.63 \pm 0.030^{*}$ & $13.4 \pm 1.15^{*}$ \\
\hline & $P<.0001$ & $P<.0001$ & $P<.0001$ & \\
\hline \multirow[t]{2}{*}{ LAVI $\left(\mathrm{mL} / \mathrm{m}^{2}\right)$} & $-0.70 \pm 0.032 *$ & $0.44 \pm 0.032 *$ & $0.45 \pm 0.023^{*}$ & $41.9 \pm 2.45^{*}$ \\
\hline & $P<.0001$ & $P<.0001$ & $P<.0001$ & \\
\hline \multirow[t]{2}{*}{ PASP (mm Hg) } & $-0.16 \pm 0.013^{*}$ & $0.076 \pm 0.013^{*}$ & $0.41 \pm 0.021^{*}$ & $21.1 \pm 0.97^{*}$ \\
\hline & $P<.0001$ & $P<.0001$ & $P<.0001$ & \\
\hline LA-LV gradient $(\mathrm{mm} \mathrm{Hg})$ & $\begin{array}{c}-0.0007 \pm 0.0021 \\
P=.75\end{array}$ & $\begin{array}{c}-0.0007 \pm 0.0020 \\
P=.74\end{array}$ & NA & $2.95 \pm 0.080^{*}$ \\
\hline
\end{tabular}

$E F$, Ejection fraction; $L V E D D$, left ventricle end-diastolic diameter; $L V E S D$, left ventricle end-systolic diameter; $L A V I$, left atrium volume index; $P A S P$, pulmonary artery systolic pressure; $L A-L V$, left atrium-left ventricle; $N A$, not available. *Statistically significant. 